\title{
Determination of DVB-T2 Signal Quality in Nigeria: A Case Study of Jos, Plateau State, Nigeria
}

\author{
E. E. C. Igbonoba*, O. Omoifo \\ Computer Engineering Department, University of Benin, Benin City, Edo State, NIGERIA.
}

\begin{abstract}
This study presents the evaluation of digital video broadcasting-terrestrial second generation (DVB-T2) Television signal quality in Jos using Integrated Television Services Limited signal. The delivery of quality Television signal remains problematic in Nigeria due to signal attenuation and degradation between the transmitter and receiver station. This is primarily due to environmental and atmospheric perturbations prevalent along the signal paths. This research aim is to determine the signal quality of DVB-T2 Television system in Jos, Plateau State. The simple field measurement methodology was adopted in measuring field strength and channel power parameters. These measurement parameters were used to calculate for carrier-to-noise ratio (CNR) and signal-to-noise ratio (SNR) through empirical method. Finally, CNR and SNR were used to determine the signal quality of DVB-T2 signal in Jos. The result of the research shows that DVB-T2 signal in the primary service areas has good and reliable signal apart from the rocky environments.
\end{abstract}

Keywords: digital video broadcasting-terrestrial, atmospheric interference, carrier to noise ratio, signal to noise ratio

\section{INTRODUCTION}

The second generation terrestrial broadcast transmission system (DVB-T2) was designed purposely to replace the analogue video broadcasting technology because of the problems of ghost images due to multipath distortion in the radio signals which degrades the quality of the analog broadcast signals [1]. The DVB-T2 is the world's most advanced digital terrestrial Television (DTT) system, offering more robustness, flexibility and at least 50\% more efficiency than any other DTT system [1]. The DVB-T2 supports standard definition (SD), high definition (HD), ultrahigh definition (UHD), mobile Television (MTV), or combination of both handheld and mobile device. It allows the simultaneous transmission of multiple services with different configurations thereby producing different robustness and quality. This system permits new type of reception scenarios for digital terrestrial signals, like mobile and handheld pedestrian reception scenarios, so DVB-T2 can be used for providing fixed outdoor, handheld, indoor and mobile services within the same channel due to the number of configurations supported [2]. The main goal of DVBT2 standard is to achieve more bandwidth compared to DVB-T, targeting high definition Television (HDTV) services, improve single frequency

\footnotetext{
${ }^{*}$ Corresponding author (Tel: +234 (0)805 823 4965)

Email addresses: igbonoba2000@live.com (E. E. C. Igbonoba), osemekhian.omoifo@uniben.edu (O. Omoifo)
}

networks (SFN), providing specific service targeting robustness, and services for fixed and portable receivers with $50 \%$ capacity throughput improvement compared to DVB-T [3].

The DVB-T2 broadcast transmission system is designed to increase capacity, ruggedness and flexibility compared to the DVB-T system while DVB-T2 Lite is the DVB-T2 profile designed to efficiently deliver Television (TV) and radio services for mobile devices such as phones and tablets [4]. This has encouraged substantial growth in the mobile communication services over the last few years [5]. It has become inevitable to transmit high quality and capacity broadcast network in Nigeria. The prediction of coverage accuracy has become extremely important in broadcasting [6]. Therefore, for more accurate coverage design of modern Television broadcast networks; signal strength, power channel, carrier-to-noise ratio (CNR) and signal-to-noise ratio (SNR) measurements must be taken into consideration in order to provide an efficient and reliable coverage area with acceptable quality TV services. During the radio wave propagation, the signal strength decreases as the distance between the transmitter and receiver increases. Moreover, the mechanisms of the electromagnetic wave propagation are diverse and can be generally classified as reflection, diffraction, and scattering. The complex propagation environment makes the prediction of the received signal strength a very difficult [7].

This research addresses the comparisons between the theoretical and the empirical propaga- 
tion analysis achievable with the most extensively used propagation data for digital television (DTV) broadcasting measurements recognized by the International Telecommunication Union (ITU). The signal attenuation and degradation may be due to effects of, free space loss, refraction, diffraction, reflection, aperture-medium coupling loss and absorption arising from both atmospheric and environmental perturbations. These perturbations are mostly prevalent within the terrain contours, environment (urban or rural, vegetation and foliage), propagation medium (dry or moist air), the signal paths between the transmitter (TX) and the receiver (RX), the height and location of antennas [8]. The coverage area of DTT can be influenced by many factors; the output power of the transmitter, the height of transmitting and receiving antenna, terrain between the transmitter and receiver, effect of meteorological parameters and foliage amongst others [9].

\section{BACKGROUND AND LITERATURE SUR- VEY}

\subsection{DVB-T2 System and Modulation}

The DVB-T2 system fulfilled technical functionalities mainly from DVB-T [10] and digital video broadcasting - satellite second generation (DVBS2) [11]. The DVB-T2, system offers meaningfully enhanced performance in mobile channels and its coding schemes greatly outperforms the forward error correction (FEC) techniques used in DVB-T higher order constellation, 256-Quadrature Amplitude Modulation (QAM), which increases the spectral efficiency and bit rate [2]. The flexibility of DVB-T2 offers other configurable parameters that could provide numerous configuration modes, providing different levels of protection and bitrates for DVB-T2 signals that could increase the robustness of the signal optimize data transmission capacity, and some combinations can be chosen to balance between robustness and transmission capacity. The DVB-T2 also provides mobile and pedestrian reception with standard definition, high definition and other services available. The DVB-T2 services and higher layer signaling data are transmitted in physical layer pipes (PLP) [12]. The system permits the transmission of multiple PLP at the same time, with different levels of coding, modulation, and time interleaving which permits one service for mobile reception and other services for fixed high definition television (HDTV) reception.

The DVB-T2 uses multiple carrier orthogonal frequency division multiplexing (OFDM) techniques, adding forward error correction (FEC) produces coded OFDM (COFDM) which improves the robustness of transmission [1]. The 64-QAM and 256-QAM are the modulation techniques used in DVB-T2 technology and Nigeria adopted 256QAM technique, delivering a gross data rate of 8 bits per symbol per carrier.

\subsection{Signal Quality Parameters Philosophy}

In this research, carrier-to-noise ratio (CNR) and signal-to-noise ratio (SNR) were used to de- termine the performance and signal quality of DVB-T2 receiver.

\subsubsection{Carrier to noise ratio (CNR)}

The $C N R$ measures the received carrier strength relative to the strength of the received noise or $C N R$ is defined as the ratio of the relative power level to the noise level in the system bandwidth. The High $C N R$ ratios provide enhanced quality of reception, and largely higher communications accuracy and reliability, than low $C N R$ ratios [13]. The $C N R$ is calculated using the following link budget formula:

$$
C N R=\frac{P_{\text {received }}}{P_{\text {noise }}}=\frac{P_{\text {received }}}{F \times K \times T_{o} \times B}
$$

where $P_{\text {noise }}=$ Received noise Input power; $F=$ Received noise figure; $P_{\text {received }}=$ Minimum receiver Input power; $B=$ Received noise bandwidth $(\mathrm{MHz}) ; K=$ Boltzman constant; $T_{o}=$ Absolute temperature (290k); $C N R=$ Carrier-to-noise ratio

$$
\begin{array}{r}
P_{\text {received }}(d B)= \\
C N R(d B)+F(d B) 10 \log _{10} B(\mathrm{MHz})-114
\end{array}
$$

The $C N R$ describes the robustness of transmission systems with respect to noise and interference. In annex, $C N R$ is used to define the signal level required to receiving a viable signal in noise and interference limited channels. Then, the determination of the $C N R$ is very importance for network planning as it gives a true picture of carrier analysis recognition or if eliminated by ambient and system noise. The $C N R$ provides a rate for the quality of a communication channel [1].

\subsubsection{Signal to noise ratio (SNR)}

The $S N R$ is the ratio of the received signal strength over the noise strength within the frequency range of operation. The noise strength may include the noise in the atmosphere or location and other unwanted signals (interference). The signal-to-noise ratio is an accepted parameter used to assess the quality of a communication link and is measured in decibels $(d B)$. Furthermore, $S N R$ is calculated as the ratio of average symbol power to noise power. The noise power includes any factor that causes the symbol to differ from the ideal state position, including additive noise, distortion and inter-symbolinterference (ISI) [14]. The $S N R$ is given as:

$$
\begin{gathered}
S N R=10 \log \left(\frac{\text { signal power }}{\text { noise power }}\right) \\
S N R=C N R-10 \log _{10} m
\end{gathered}
$$

where $m=\log _{2} M$ for $M-\mathrm{QAM}$ in DVB-T2, $M=$ 64 or $256 ; F=6 d B$ and $B=7.71 \mathrm{MHz}$ for carrier mode $8 \mathrm{k}$ for $8 \mathrm{MHz}$ channel.

The DVB-T2 signal was determined in this research work using the combination of $C N R$ and $S N R$ calculated from the field measurements. Results obtained from the measured channel power in decibel millivolts $(\mathrm{dBmV})$ were converted to receive power in $\mathrm{dBm}$. 


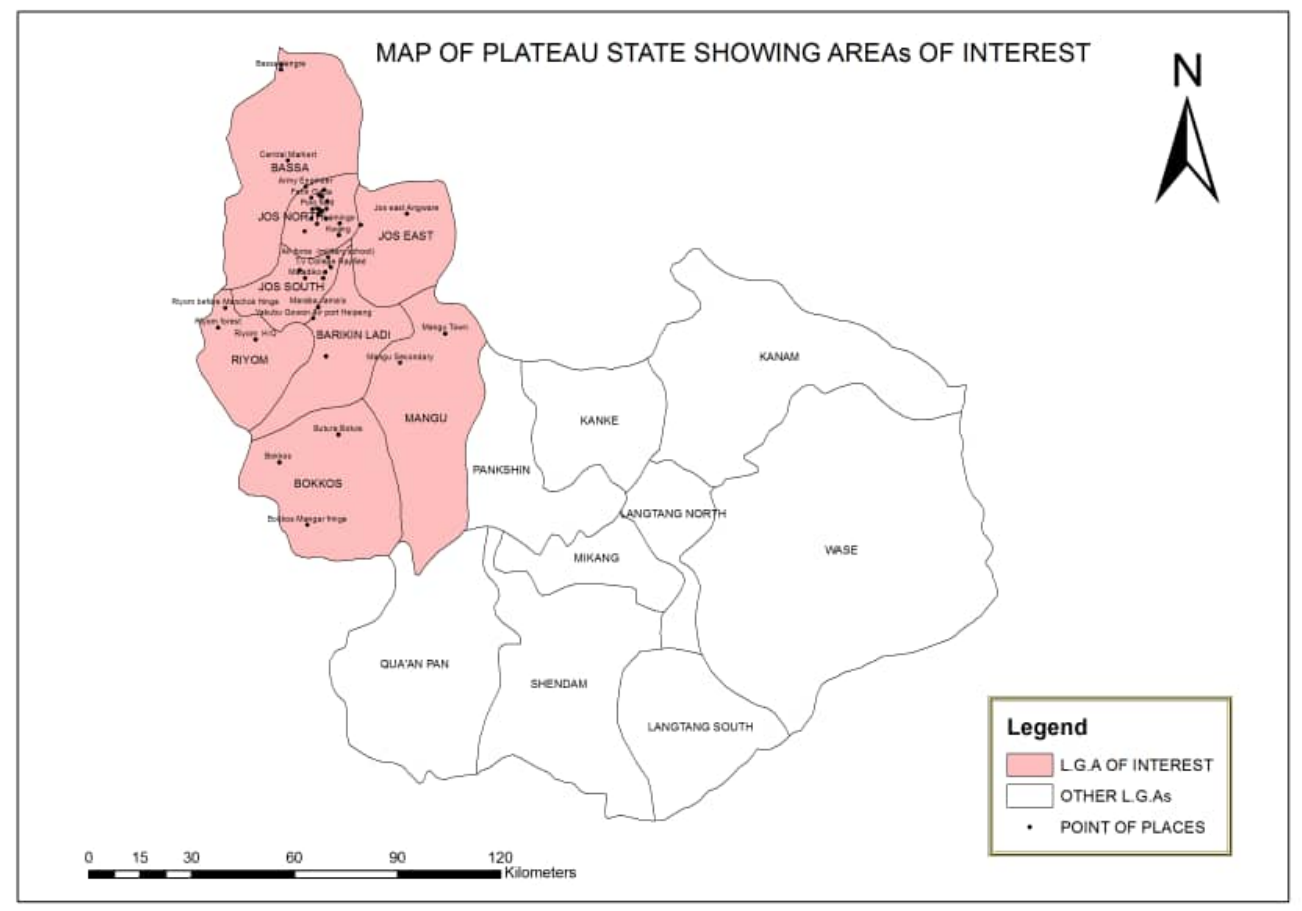

Figure 1: Geographical Map of Plateau State [15]

\subsubsection{Empirical calculation}

Firstly, $C N R$ was obtained using the formula in Eq. (2), where $F$ is receivers noise figure $=6$ $\mathrm{dB}, B$ is receivers noise bandwidth $=7.71 \mathrm{MHz}$, $P_{t}$ is the transmitted power $=61.14 \mathrm{~dB}, P_{r}=\mathrm{Re}-$ ceived Power at the location obtained from the Channel Power; Noise factor for DVB-T2 $=-114$. Note, the maximum threshold for $C N R$ in DVB$\mathrm{T} 2$ environment is $\leq 70 \mathrm{~dB}$ [1]. The conversion from channel power $(\mathrm{dBmV})$ to received power in milli-decibel $(\mathrm{dBm})$ was done using A.H systems Inc. or Cantwell Engineering -useful formulas for radio frequency $(\mathrm{RF})$ related conversions [16];

$$
P_{r} \mathrm{dBm}=C_{p}-10 \log _{10}(z)-30
$$

Where $\mathrm{P}_{r}$ is the received power in $\mathrm{dBm}, \mathrm{C}_{p}$ is the channel power in $\mathrm{dBmV}, z$ is the impedance given to be $70 \Omega$ in broadcasting while $50 \Omega$ in Telecom. Secondly, SNR was calculated using the formula in Eq. (4). The Table 1 presents the threshold values for $C N R$ in DVB-T2 environments for fixed reception.

Table 1: The $C N R$ threshold in DVB-T2 environment $[1,17]$

\begin{tabular}{llll}
\hline S/N & Environment & $\begin{array}{l}\text { CNR } \\
\text { mum) }\end{array}$ & (mini- $\begin{array}{l}\text { CNR } \\
\text { mum) }\end{array}$ \\
(Maxi- \\
\hline 1 & Rural & 20 & 70 \\
2 & Sub-Urban & 22 & 70 \\
3 & Urban & 24 & 70 \\
\hline
\end{tabular}

\section{MATERIAL AND METHODS}

This section presents the measurement and readings of DVT-T2 Television signal levels in different locations around Jos and its environs, Plateau State, Nigeria. The measurement campaign was carried out in the 2019 covering the two major seasons. The measurement in the wet season was done in the month of July and August on route $\mathrm{A} 1$ and $\mathrm{B} 1$ while the dry season accommodated route $A_{2}$ and $B_{2}$ in the month of November and December. This is to establish the effect of weather on digital terrestrial television (DTT) signal compared to the terrain. The locations on route $A_{1}$ and $A_{2}$ are same route but measured in different seasons while route $B_{1}$ and $B_{2}$ remain sane route as in route $A$ across the assumed coverage area of the DVB-T2 TV signals. The signal from Integrated Television services (ITS) was used for the measurement campaign. The network (ITS) has operating frequency of $522 \mathrm{MHz}$ as allotted by National Broadcasting Commission (NBC) and is the only DVB-T2 network operator (free-to-air) in Plateau State at the time of this research; below is ITS network parameters:

\section{Operating frequency: $\quad 522 \mathrm{MHz}$}

Effective isotropic-

radiated power (EIRP): $62.14 \mathrm{dBm}$

Tx antenna height: $\quad 107 \mathrm{~m}$

Tx coordinate: $\quad$ Latitude: $9.89^{\circ}$,

Antenna pattern: Horizontal -

Horizontal -
Omnidirectional

The map in Fig. 1 presents the geographical location of the seventeen (17) Local Government Areas (LGA) of the State with the signal coverage area. The map was downloaded from www.researchgate.net and modified to suite my purpose using geographical information system 
software (ArcGIS).

In carrying out a detail DVB -T2 signal measurement to establish the methodology used in this research; the following components for conducting measurement in the field was taken seriously i.e. Measurement Environment, Measurement Parameters, Measurement Tool, Measurement Plans/layout, Measurement Procedures/Technique and Data presentation.

The choice of plateau state for the measurement campaign was predicated on the fact that the state was used for the digital switch over (DSO) pilot programme in Nigeria. During the measurement exercise, the DTT signal was present in only eight (8) Local Government Areas (Jos North, Jos East, Jos South, Bassa, Riyom, Barkin Ladi, Bokkos and Mangu) and the measured locations were ninety six (96) across route $A_{1}, A_{2}, B_{1}$ and $B_{2}$ (24 locations each). It was observed that the parent signal could not go beyond eight Local Government Area of Plateau State except with the help of Direct-to-Home (DTH) service or the introduction of repeater and booster station which was not available at the time of this measurement. However, the perturbations that may affect the smooth transmission of signal from the DVB-T2 transmitter to the receiver were put into consideration during the measurement.

The key parameters measured with the Deviser E8000A spectrum analyzer were field strength $(\mathrm{dB} \mu \mathrm{V} / \mathrm{m}$ - decibel microvolts per meter) and channel power (dBVm - decibel volts meter) only. To ensure high stability and relative precision using spectrum analyzer in carrying out field measurement in broadcasting, ITU recommendations on field measurement, relevant equipment and settings specified in [15] were followed to adopt specified ITU regulations The measurement tool for the field test system comprise of test equipment carried in a Van and driven to test locations within the selected areas. The test equipment used as presented in Fig. 2 include:

A. A Deviser Spectrum analyzer E8000A series parameter

B. A Calibrated Logarithmic Antenna parameters

C. Dedicated decoder (Digital Terrestrial Receiver) capable of decoding SDTV and HDTV (DVB-T2) signals within $460-800 \mathrm{MHz}$ carrier frequencies.

D. A Television monitor capable of displaying SDTV and HDTV (DVB-T2) signals

E. Global positioning satellite (GPS) enable smart phone

\section{F. $75 \Omega, 15 \mathrm{~m}$ RF cable and connectors}

The set-up for field strength, channel power and reception quality measurement (ground and rooftop level) procedure was carried out to achieve acceptable result as laid down by ITU; (frequency managers, monitoring services, broadcasters etc.). Below are the steps:
1. The equipment is connected as shown in Fig. 2

2. The antenna was raised 10 -meters above ground level

3. The antenna was oriented for maximum signal level considering the DVB-T2 transmitter clear line-of-sight and other obstacles on the transmitter path

4. The field strength of DVB-T2 signal was measured and recorded

5. The channel power of DVB-T2 signal and the noise level were measured and recorded

6. The reception quality of the decoded signal was assessed.

7. The coordinates of the location was taken with Google earth map and recorded

8. The above steps were repeated three times at each location.

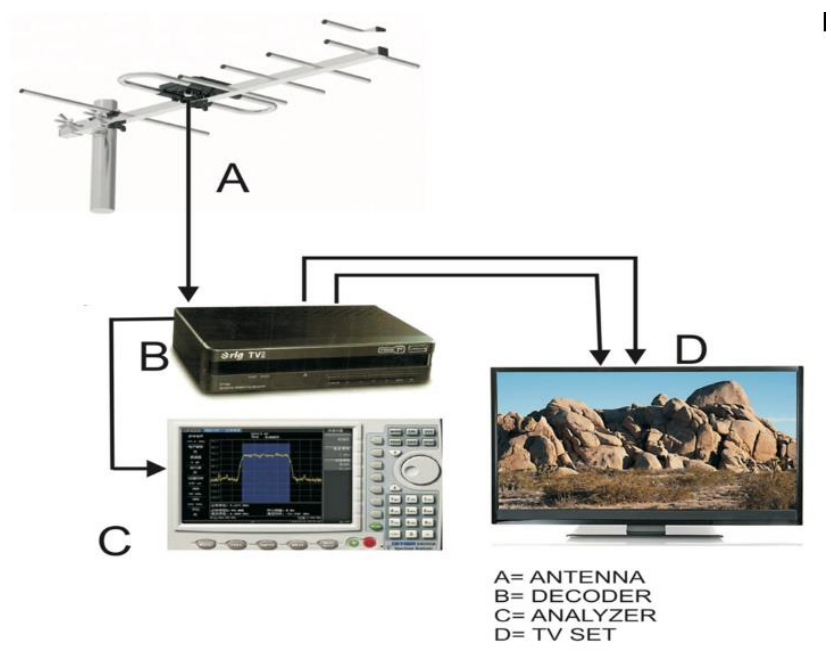

Figure 2: Equipment Setup for Field Measurement

\section{RESULT AND DISCUSSION}

The signal quality analysis was carried out using $C N R$ and $S N R$ parameters. The graphs in Fig. $3-6$ present the result of the $C N R$ versus distance and $S N R$ distance in logarithm. The Fig. 3 and 4 present results greatly influenced by terrain due to rocky hill at DU Community in Jos South Local Government Area while Fig. 5 and 6 were free from such influence because none of the measured locations were located in such terrain. However, the general results presented in Fig. 3 -6 showed how weather influenced the measurement outcome (route $\left.A_{1}-A_{2}\right)$ and $\left(B_{1}-B_{2}\right)$ in relation to distance. The results obtained from the different routes recorded the following values in Table 2 showing highest and lowest values in the measured routes. 


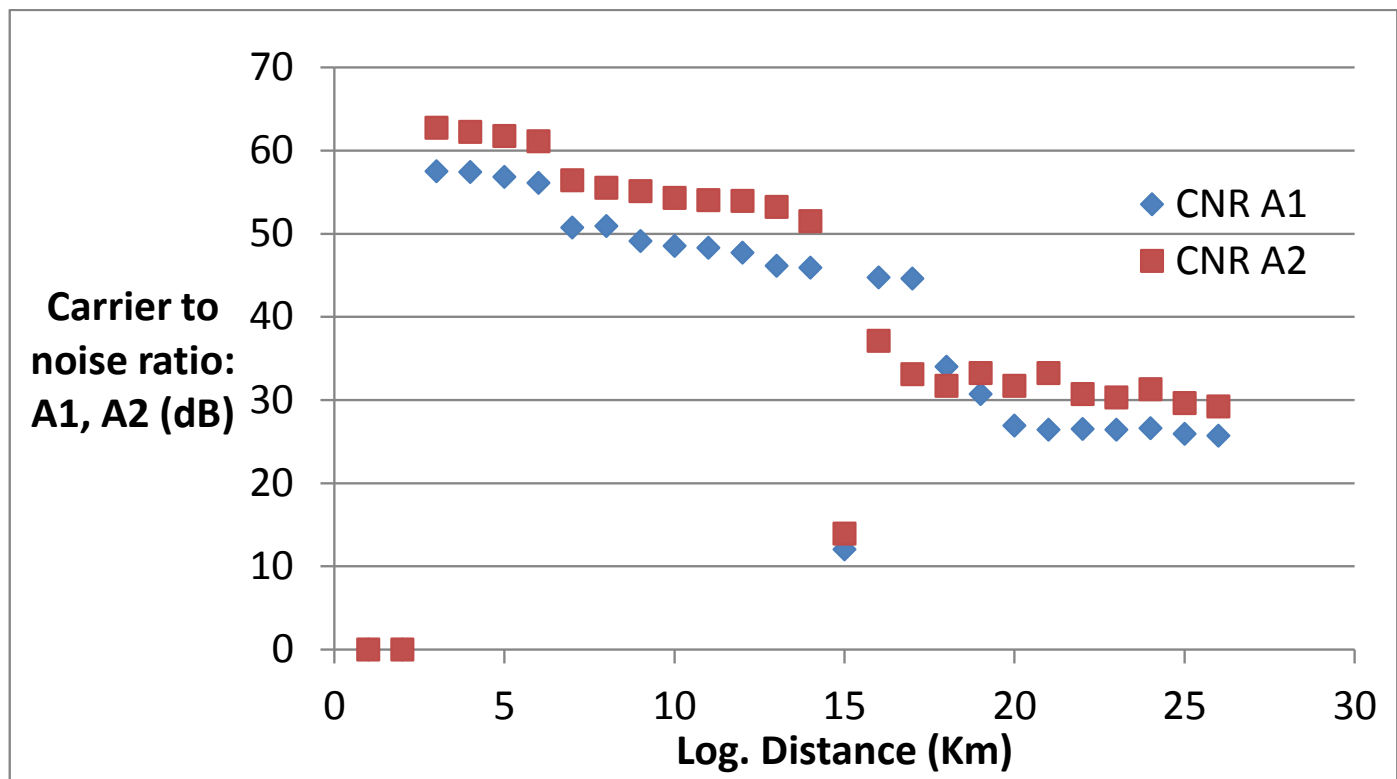

Figure 3: Graphs of $C N R$ vs. $\log$ distance for route $\mathrm{A}_{1}, \mathrm{~A}_{2}$

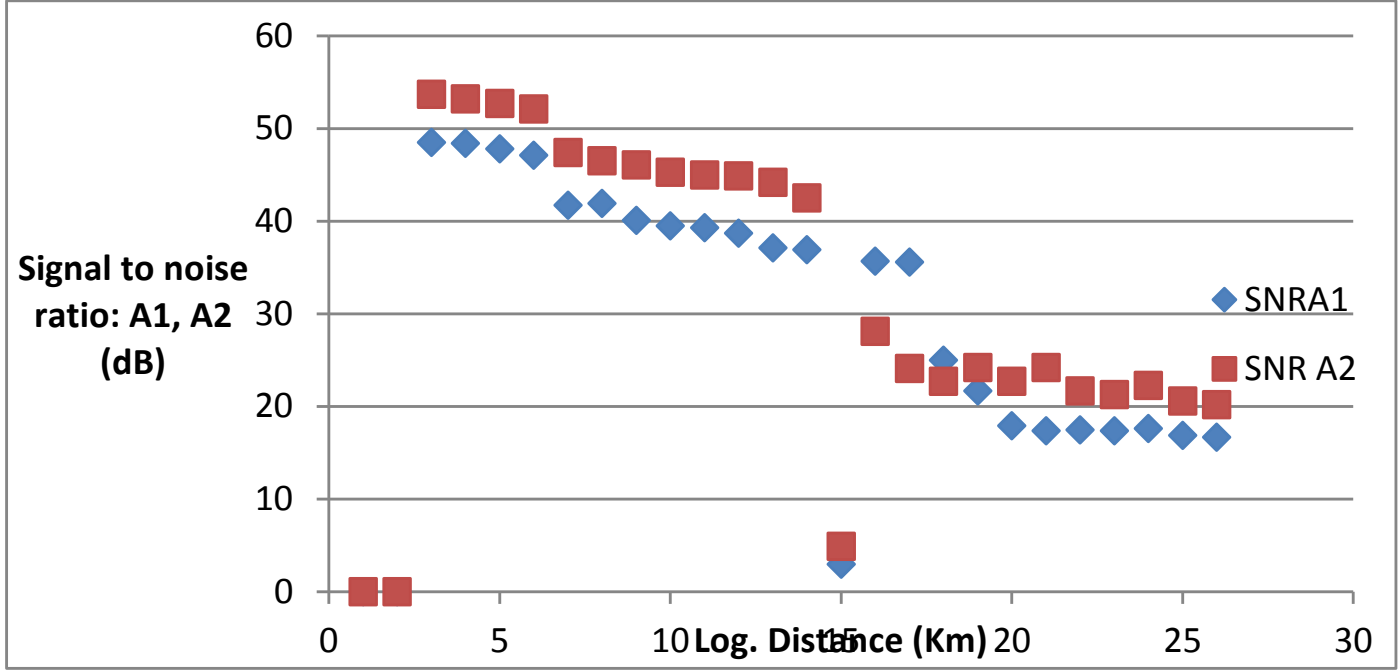

Figure 4: Graphs of $S N R$ vs. $\log$ distance for route $\mathrm{A}_{1}, \mathrm{~A}_{2}$

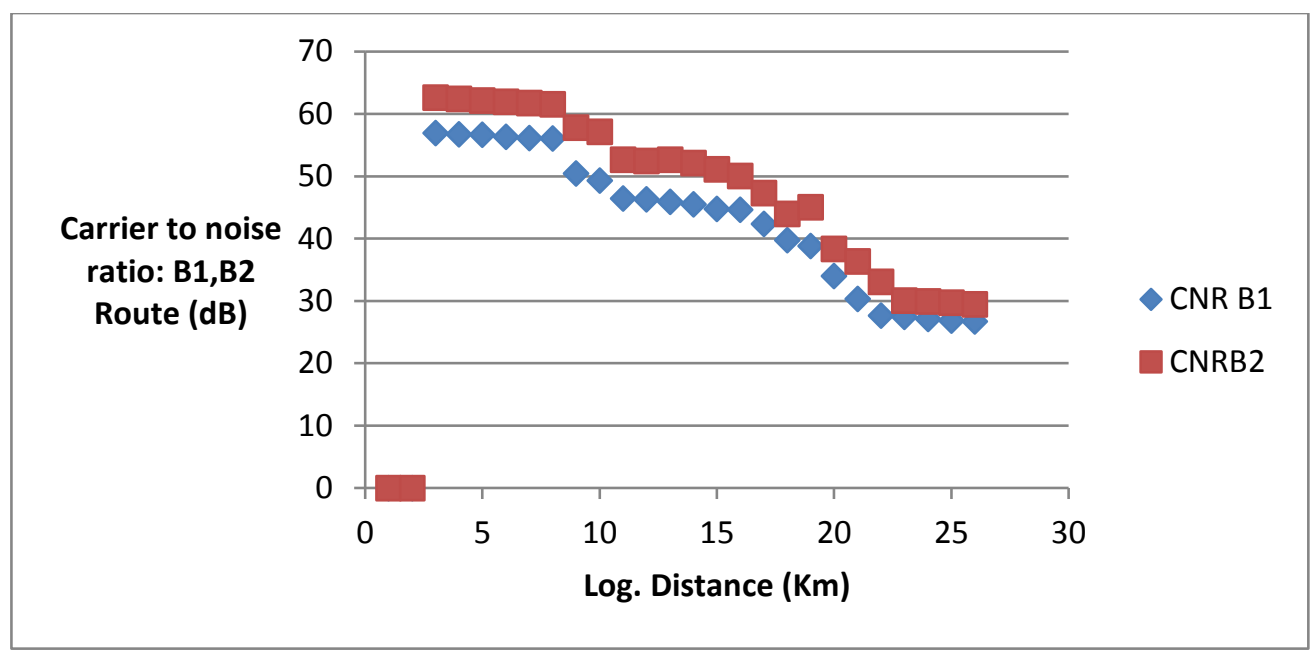

Figure 5: Graphs of $C N R$ vs. $\log$ distance for route $\mathrm{B}_{1}, \mathrm{~B}_{2}$ 


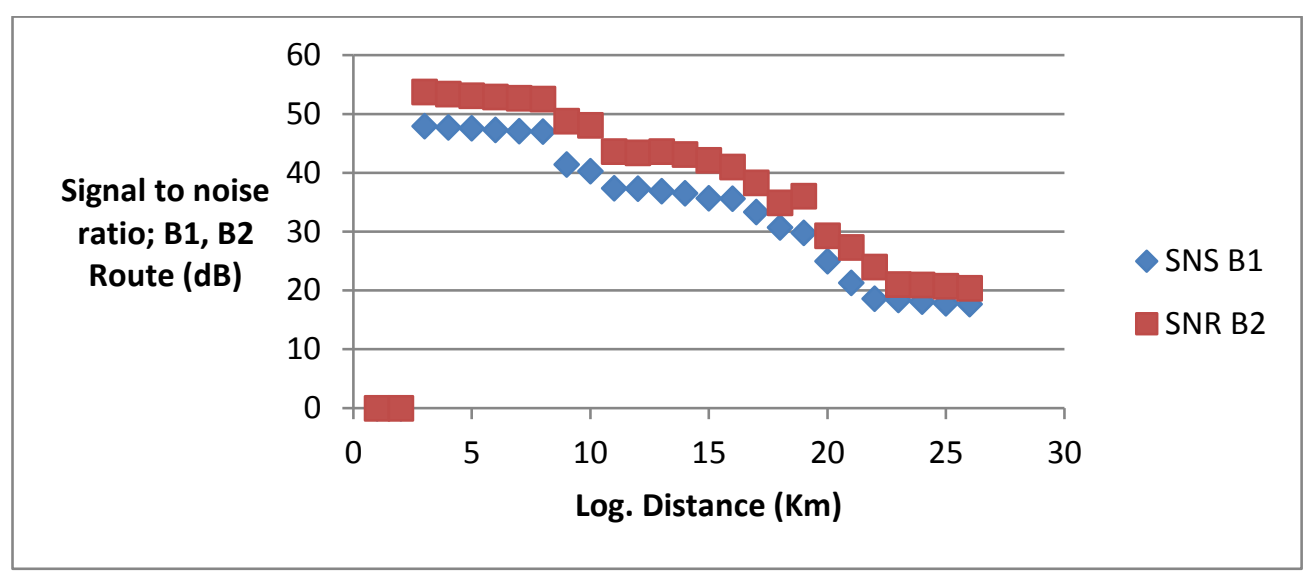

Figure 6: Graphs of $S N R$ vs. $\log$ distance for route $\mathrm{B}_{1}, \mathrm{~B}_{2}$

Table 2: The Data showing Highest and Lowest Values in the Different Routes

\begin{tabular}{lllll}
\hline Parameters & $\begin{array}{l}\text { Route } \\
\mathbf{A}_{1}\end{array}$ & $\begin{array}{l}\text { Route } \\
\mathbf{A}_{2}\end{array}$ & $\begin{array}{l}\text { Route } \\
\mathbf{B}_{1}\end{array}$ & $\begin{array}{l}\text { Route } \\
\mathbf{B}_{2}\end{array}$ \\
\hline CNR (dB) & & & & \\
Highest value & 57.53 & 62.73 & 56.93 & 62.63 \\
Lowest value & 12.03 & 13.93 & 26.73 & 29.43 \\
\hline SNR (dB) & & & & \\
Highest value & 48.5 & 53.7 & 47.9 & 53.7 \\
Lowest value & 3 & 4.9 & 17.7 & 20.4 \\
\hline
\end{tabular}

The Table 2 equally explained the variations record between the wet and dry seasons.

Furthermore, the results obtained from the field equally presented some significant signal variation arising from terrain obstruction between the two parameters along route $\mathrm{A}_{1}$ and $\mathrm{A}_{2}$.

The fluctuation was experienced in location 12 , 13 and 14, CNR and $S N R$ fluctuated from $(C N R$ : 45.93 - 12.03 - $44.73 \mathrm{~dB}, S N R: 36.9-3$ - $35.6 \mathrm{~dB}$ ) which shows a strong divergence as a result of signal obstruction from its line-of-sight (LOS) as a result rocky hill in Du community as stated above.

The relationship between the $C N R$ and $S N R$ is directly proportional because increase in $C N R$ leads to increase in $S N R$ in Fig. 7 to 10 or alternatively decrease in $C N R$ leads to decrease $S N R$. The locations with very good reception/high signal levels are environments with little or no reflections with regards to good line-of-sight (LOS) between the receiver and the digital transmitter. Jos is considered to be semi-urban city with little high-rise buildings which contributed to good reception with high quality signals. The $S N R$ and $C N R$ were found to be very high in some areas because the digital signal has high field strength and with few obstacles blocking the LOS between the TX and RX. Sufficiently, the digital transmitter is well serving Jos and its environs apart from the occasional weak signals experienced during heavy downpour and degraded signals due to rocky hills in the neighborhoods like Du community. However, these obstructions due to rocky hills blocks TV consumers from receiving very high signals or alternatively experience signal failure due to difficult terrain. The DTT signal strength degrades due to obstructions arising from terrain, effect of rain and propagation pathloss caused by long distance from the transmitter to the receiver but more importantly, the terrain affects the DTT signal more.

\section{FINDINGS}

The following were found in this study:

1. The DVB-T2 signal is only available in eight (8) Local Government Area of Plateau State but with strong presence in only six (6) LGA judging from the results obtained from the field. The remaining nine (9) Local Government Areas are without DTT signal.

2. It was found that obstacles such as rocks and hills from Jos and its environs have a great influence on signal attenuation and degradation. The signal loss or attenuation is not only subject to diffraction cause by obstruction but also the emission of gases from the rocks heavily attenuates the signal strength.

3. It was found that rain has tremendous effect on DVB-T2 signals by degrading the signal strength (Example locations measured twice during sunlight and rain produced different results showing the level of signal degradation associated with the rain).

\section{CONCLUSION}

The DVB-T2 transmission network (transmitter) has almost the same reach with the analogue Tx but with less transmitting power due to the lower reception signal level. Most areas within the primary service areas had good and reliable signal (coverage and quality) apart from difficult terrains with rocky hills and mountains that experienced very poor reception. High rocky hills were observed to be causing signal obstructions in communities like Du with very low signal due to its location (at the base of a rocky hill). It would be significant to deploy direct-to-home (DTH) for effective coverage in such location. With favorable 


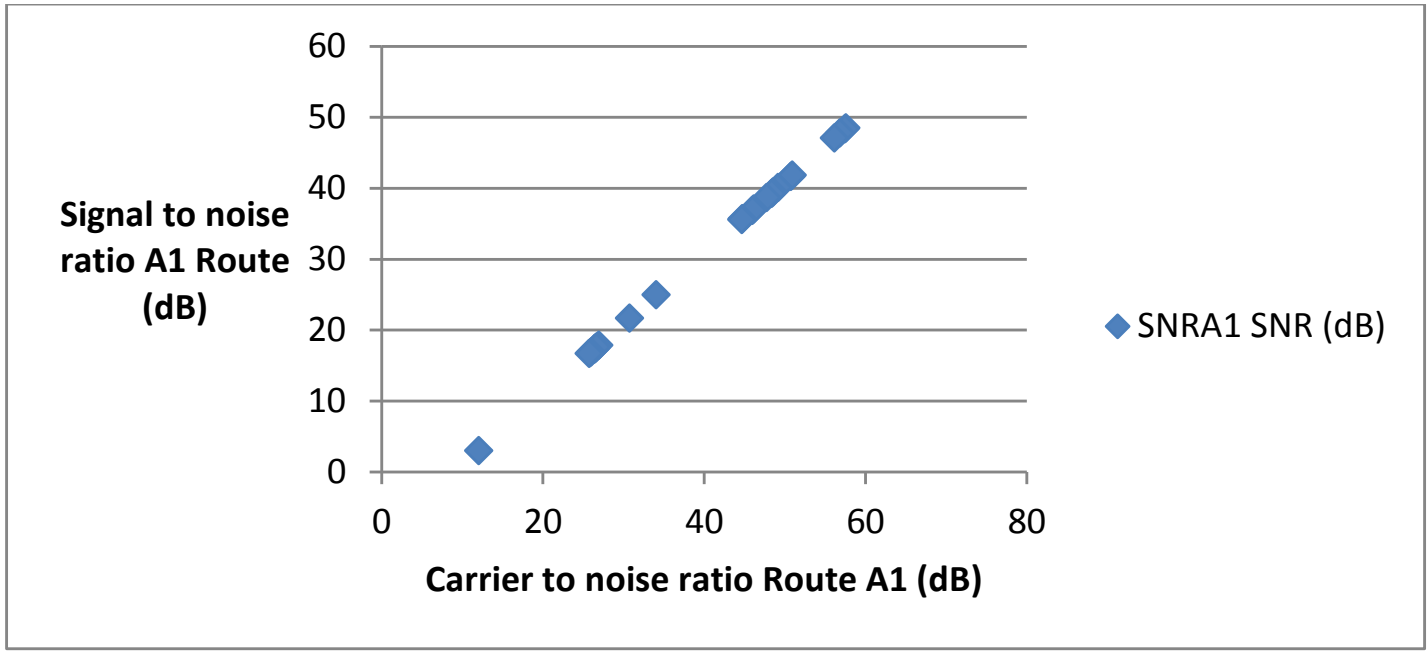

Figure 7: Graphs of $S N R$ vs. $C N R$ for route $\mathrm{A}_{1}$

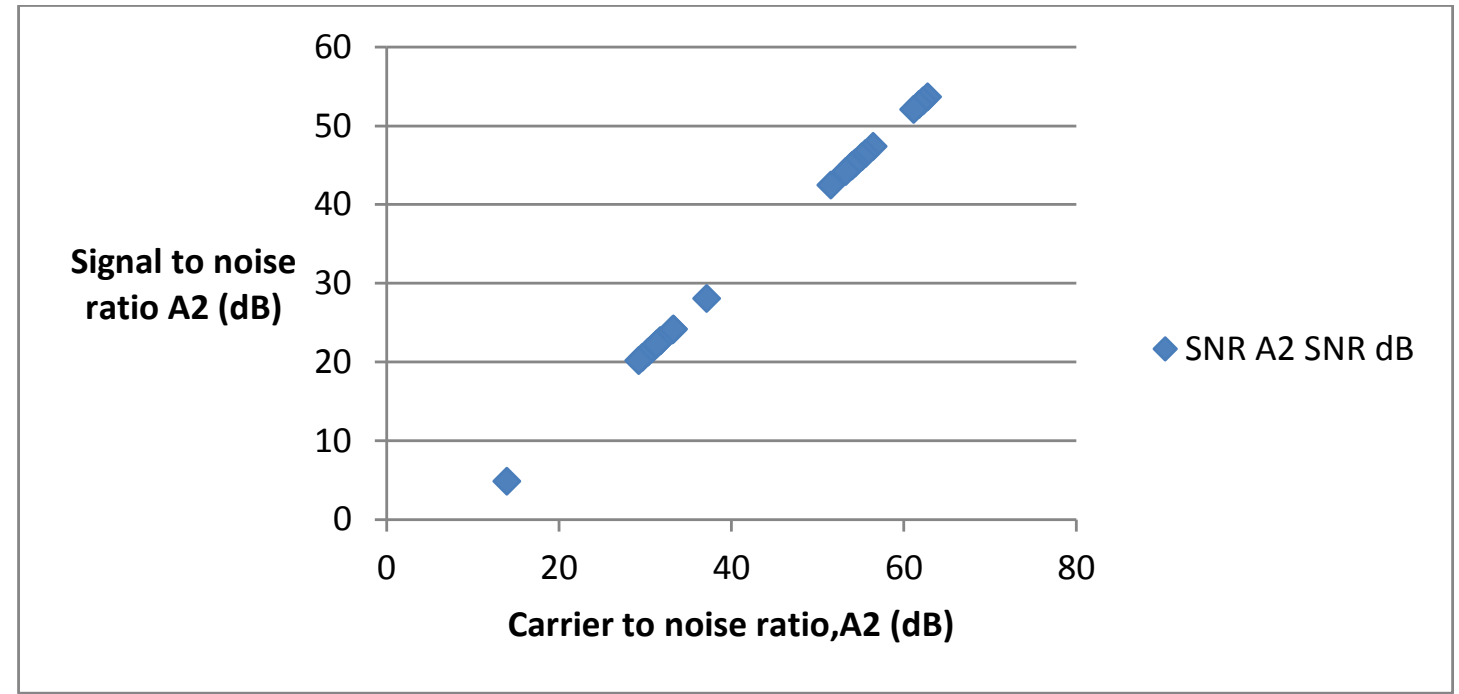

Figure 8: Graphs of $S N R$ vs. $C N R$ for route $\mathrm{A}_{2}$

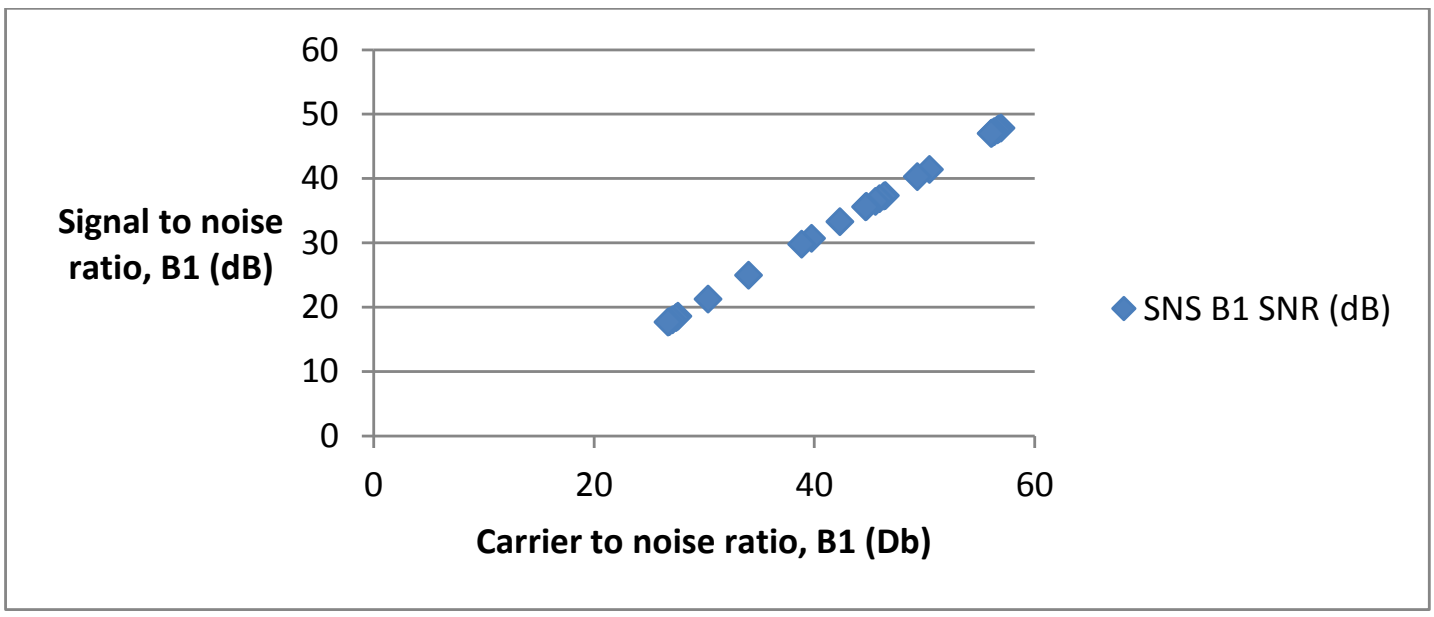

Figure 9: Graphs of $S N R$ vs. $C N R$ for route $\mathrm{B}_{1}$ 


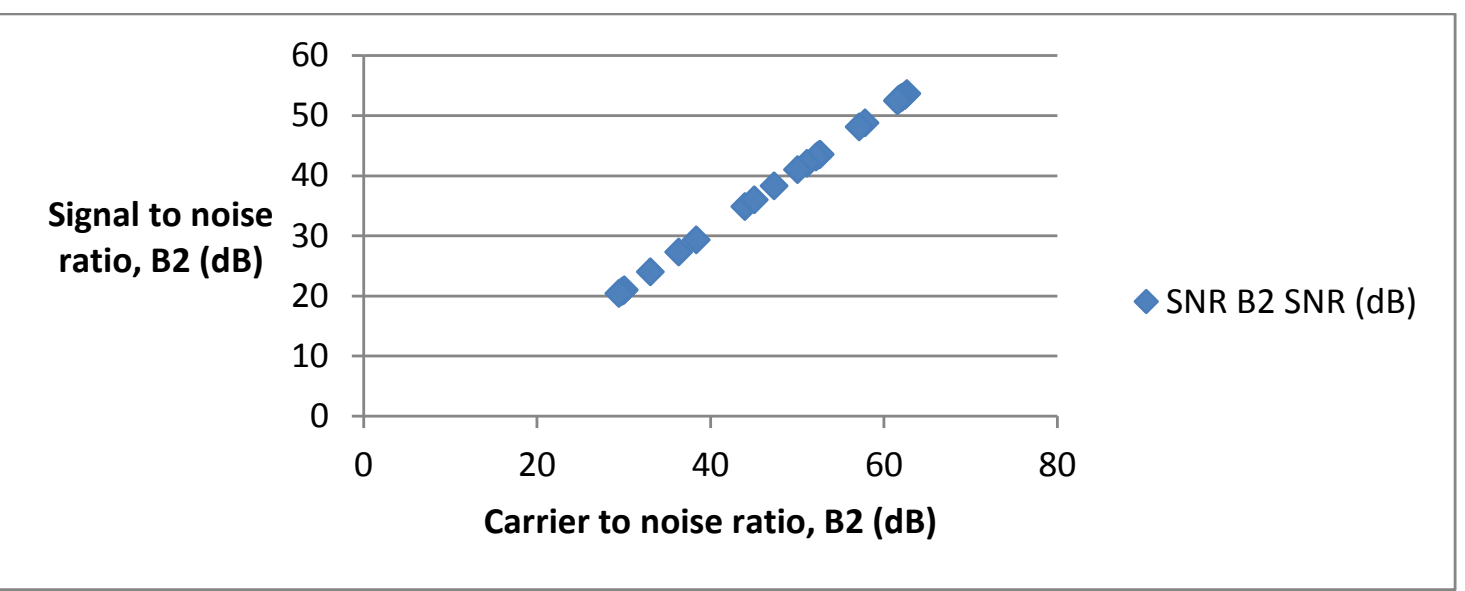

Figure 10: Graphs of $S N R$ vs. $C N R$ distance for route $\mathrm{B}_{2}$

terrain, strong and reliable signal is guaranteed. The results obtained from the field measurement equally showed that rain have tremendous effect on DVB-T2 signal in Jos. However, Jos has a lot of perturbations impeding on the signal strength and quality arising from both terrain and weather but the terrain obstructs more. These research findings will assist in system design and enhanced network deployment in Plateau State, Nigeria.

\section{References}

[1] K. Lusekelo and S. Anael, "Performance Evaluation of Dvb-T2 Network and Its Optimization Recommendations a Case of Dar Es Salaam, Tanzania," International Journal of Advanced Research in Computer Science and Software Engineering, vol. 4, no. 4, 2014.

[2] G. Berjon-Eriz, I. Eizmendi, and M. Vélez, "Performance Evaluation Procedure for Mobile DVB-T2 Reception in Urban Environments," Journal of Department of Electronics and Telecommunications Engineering, pp. 11-89, 2011.

[3] L. Kondrad, I. Bouazizi, and V. K. Vadakital, "CrossLayer Optimized Transmission of H.264/SVC Streams over DVB-T2 Broadcast System," in IEEE International Symposium on Broadband Multimedia Systems and Broadcasting 2009, BMSB'09, 2009, pp. 1-5.

[4] ITU-R, "DTTB handbook: Digital terrestrial television broadcasting networks and systems implementation," Geneva, October 2016.

[5] K. Cetin and K. Begum, "Measurement and evaluation of electric field strength in samsun centre," International Journal of Applied Mathematics, Electronics and Computers, no. 4, pp. 24-29, 2016, http://ijamec.atscience.org.

[6] Z. Nadir, N. Elfadhil, and F. Touati, "Path-loss determination using Okumura-Hata Model and spline interpolation for missing data for Oman," in Proceedings of the World Congress on Engineering 2008, London, U.K, 2-4 July 2008.

[7] Z. Yan, W. Jinxiao, and Y. Guanshu, Path-loss Prediction Based on Machine Learning: Principle, Method, and Data Expansion. School of Information and Electronics, Beijing Institute of Technology, Beijing 100081, China: MDPL, May 2019.

[8] D. Shalangwa and G. Jerome, "Path loss Propagation model for Gombe Town, Adamawa State, Nigeria," International Journal of Computer Science and Network Security, vol. 10, no. 6, pp. 186-190, 2010.

[9] A. Akinbolati, M. O. Ajewole, and A. Adediji, "Propagation curves and coverage areas of digital terrestrial television base stations in the tropical zone," Heliyon, vol. 6 , no. e03599, pp. 2405-8440, 2020.
[10] ETSI EN 300 744, "Digital Video Broadcasting (DVB); Framing Structure, Channel Coding and Modulation for Digital Terrestrial Television (DVB-T)," ETSI EN 300744 , vol. 1, no. 2, January 2009.

[11] ETSI EN 302 307, "Digital Video Broadcasting: Second Generation Framing Structure, Coding and Modulation Systems for Broadcasting, Interactive Services, News Gathering and other Broadband Satellite Applications," ETSI EN 302 307, vol. 1.2.1, August 2009 .

[12] ETSI EN 302 755, "Digital Video Broadcasting (DVB); Frame structure channel Coding and Modulation for a Second Generation Digital Terrestrial Television Broadcasting System (DVB- T2)," ETSI EN 302 755, vol. 1.2.1, February 2011.

[13] "Frequency and Network Planning Aspects of DVB-T2," B. Series, 2012.

[14] World-Mobile-Congress. (2014) Wireless communication design and test solutions. [Online]. Available: www.wireless.agilent.com

[15] (2019, December) Map. [Online]. Available: https://www.researchgate.net/figure/ Map-of-Plateau-state-Nigeria

[16] (2019) Useful Formula for RF Related Conversion. Cantwell Engineering. [Online]. Available: www. cantwellengineering.com

[17] ITU-R BT.2383-1, "Characteristics of digital terrestrial television broadcasting systems in the frequency band 470-862 mhz for frequency sharing/interference analysis," October 2016. 